\title{
Characterization of pore structure, gas adsorption, and spontaneous imbibition in shale gas reservoirs
}

\author{
Xianfu Huang ${ }^{\text {a,b }}$, Ya-Pu Zhao ${ }^{\text {a,b, * }}$ \\ ${ }^{a}$ State Key Laboratory of Nonlinear Mechanics, Institute of Mechanics, Chinese Academy of Sciences, Beijing 100190, People's Republic of China \\ ${ }^{\mathrm{b}}$ School of Engineering Science, University of Chinese Academy of Sciences, Beijing 100049, People's Republic of China
}

\section{A R T I C L E I N F O}

\section{Keywords:}

Shale gas

Nuclear magnetic resonance

Slit pore

Occurrence state

Fluid transport

$\mathrm{X}$-ray nano-CT

\begin{abstract}
A B S T R A C T
The multiscale pore structure and its distribution as well as the occurrence state of shale gas and spontaneous imbibition in gas shale are studied experimentally. Most of the pores within organic matters are at nanoscale and are isolated in all directions. They have low porosity and connectivity, which account for the most of pore volume and determine the resource abundance of gas shale reservoirs. The contents of adsorption gas and free gas in the multiscale pore structure of shale rocks increase with the increase of gas pressure, of which the free gas increases faster than that of adsorption gas. The spontaneous imbibition shows the fast shift of $T_{2}$ peaks to right at early stage of fluid transport through the interconnected network of pore structure in shale rocks. Our results may provide unified methods for clear understanding of the pore structure and fluid transport behavior in shale gas reservoirs and assist the future efficient exploitation of shale gas.
\end{abstract}

\section{Introduction}

Hydrocarbon production from shale gas reservoirs is playing an everincreasing role in world energy supply today because of its enormous reserves and low greenhouse gas (GHG) emissions. Beyond, shale gas is not just good for the energy conservation and emission reduction-it is in line with the global momentum of clean energy (Tomain, 2012) and has the potential to replace petroleum as a new energy. Shale gas is an unconventional gas trapped in shale formations, where the local geological conditions lead to the great difficulty for gas recovery. Almost 70\%-85\% gas gets stuck to the shale matrix by adsorption (Das, 2012; Ross and Bustin, 2007; Zeng et al., 2014). In addition, the porosity and the permeability of shale beds are ultra-low, whose magnitudes are typically 1-6 orders below that of conventional gas reservoirs (Lee et al., 2016; Maurel et al., 2010). The shale gas reservoirs are usually buried in the deep underground thousands of meters below. It has been estimated that only $5 \%-15 \%$ content of the shale gas gets extracted by gas recovery (Bažant et al., 2014). If the enhanced gas recovery (EGR) increases by $8.2 \%$, much cost can be cut down which is equivalent to drill a new gas well.

The shale gas reservoirs are featured by complex pore structure with different size, distribution, shape and curvature, which exert a great impact on gas storage. In previous studies, the simulation tools such as molecular dynamic (MD) provide a unique window to look into the details of critical aspects in gas adsorption and desorption. Wu et al. (2015a) conducted MD simulations about the adsorption and displacement of gas in nanochannels, and found that the smaller slit pore stores more gas content under relatively low pressure. Zhu and Zhao (2014) proposed that there exists an optimal pore diameter for maximizing the adsorption capacity of methane in pore. They also established the equation of state for adsorption gas in nanopores by considering the disjoining pressure, and performed MD simulations to study the gas structure in nanopores under different external environments and fluid properties, which clarified the dependency of capillary condensation on pore size and curvature (Zhu and Zhao, 2014). Mosher et al. (2013) found that the adsorption amount of shale gas increases with pore size decreasing. Chen et al. (2017) found that the variation of pore-throat size may explain the adsorption hysteresis of shale gas in nanopores.

When the shale gas desorbs from the pore, it usually flows to the natural fracture then to the artificial fracture, and finally reaches to the gas well. Fig. 1 shows the fluid flow regimes in these multiscale channels depending on the Knudsen number $K n=\lambda / L(\lambda$ and $L$ are the mean free path of gas molecule and the characteristic length of channel, respectively). When the pore-throat size is at nanoscale that comparable to the molecule $(K n>10)$, the molecule experiences a force field from the pore wall, resulting in extremely complex flow mechanisms. The dominated flow in this regime is free molecular flow, i.e., the Knudsen diffusion or surface diffusion, in which the classical Darcy law does not work

\footnotetext{
* Corresponding author. State Key Laboratory of Nonlinear Mechanics, Institute of Mechanics, Chinese Academy of Sciences, Beijing 100190, People's Republic of China.

E-mail address: yzhao@imech.ac.cn (Y.-P. Zhao).
} 
a

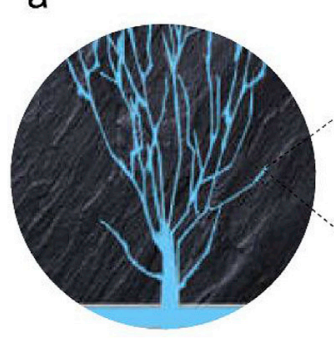

b

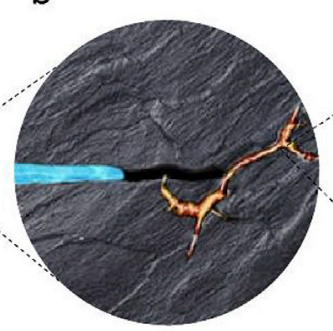

C

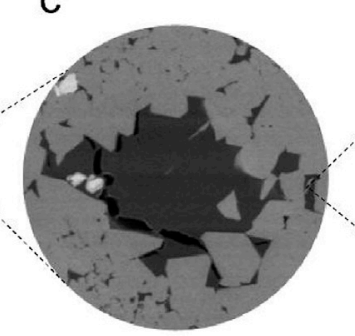

d

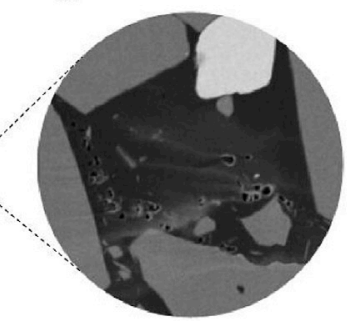

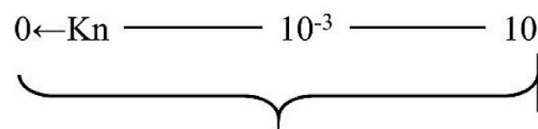

Continuum flow

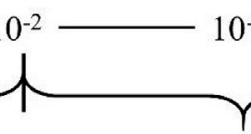

Slip flow

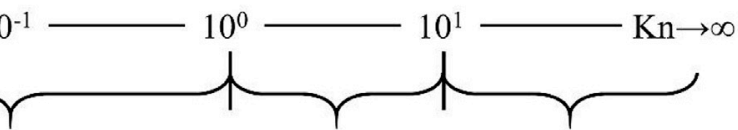

Transition flow Free molecular flow

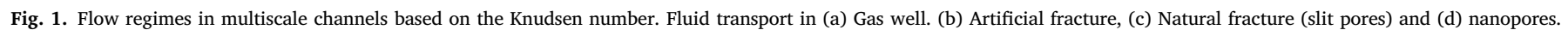

anymore (Monteiro et al., 2012; Swami et al., 2012; Wang and MarongiuPorcu, 2015). As the pore-throat size increases, the transition flow and the slip flow take over, in which the interaction frequency of gas-gas molecules exceeds that of the gas-pore wall. When the channel size is much larger than that of gas molecule, the continuum flow (HagenPoiseuille flow) dominates. Javadpour (2009) and Darabi et al. (2012) proposed a apparent permeability with Knudsen diffusion and convection taken into account, which simplified the flow formula into the form of Darcy law by replacing the permeability. However, the surface diffusion was not considered in the model, yet it may be the dominated flow in shale gas recovery (Sheng et al., 2015; Wu et al., 2015b). Moreover, fluid transport behavior during the spontaneous imbibition of shale rocks is of significant for shale gas recovery (Li and Horne, 2004), while there is lack of efficient experimental method to investigate the water flowing process.

The macroscopic breakthroughs of shale gas recovery show an increasingly dependency on the microscopic achievements, which raise the broader interest and requirements of microscopic studies. Although there have been some sound explorations (Liu et al., 2016; Sander et al., 2017; Ma et al., 2016; Ambrose et al., 2010; Jiang et al., 2016; Yuan et al., 2015), yet it is still insufficient to uncover the complex mechanism of fluid transport in multiscale pore structure of shale gas reservoirs. It is due to the lack of field data and knowledge of pore structure, occurrence state of shale gas and fluid transport behavior in shale gas reservoirs that restrict the efficient exploitation of shale gas. Further, the experiments for investigating the fluid transport behavior during the spontaneous imbibition shale rocks are seriously deficient for the gas recovery (Roychaudhuri et al., 2013).

In this paper, we first carry out experiments using unified methods including nuclear magnetic resonance (NMR), scanning electron microscopy (SEM) and X-ray nano computed tomography (nano-CT) in combination to experimentally study the multiscale pore structure and its distribution, size, shape and maturity of organic matters which relate to the resource abundance and the value for exploitation and development. Then, occurrence state of shale gas under different pressures and spontaneous imbibition in the interconnected pore structure in shale rocks are studied and discussed.

\section{Materials and experiments}

In this study, the shale samples were drilled from a $3 \mathrm{~km}$ underground shale gas well in Ordos Basin, China. The shale samples were all first soaked in distilled water with a vacuum pressure (15 MPa) impregnation treatment for $24 \mathrm{~h}$. The samples prepared for the gas adsorption and fluid transport experiments were then drying at $90{ }^{\circ} \mathrm{C}$ for $4 \mathrm{~h}$.

In this study, the NMR experiments were carried out to investigate the porosity, the multiscale pore structure and its distribution of shale rocks using the low-field NMR (LF-NMR) system (Niumag, MacroMR12-150HI) with a resonant frequency of $12.8 \mathrm{MHz}$ and magnet strength of $0.28 \mathrm{~T}$ at $32{ }^{\circ} \mathrm{C}$. The LF-NMR is a powerful technique that can probe the motion status of molecules inside the pores, pore structures of rocks, the course of reaction and their relations, etc. The LF-NMR system was also used to perform gas adsorption and fluid transport experiments. The Carr-Purcell-Meiboom-Gill (CPMG) sequence was used in the experiments. The parameters for the NMR experiments are listed in Table 1. Fig. 2a shows a schematic diagram of the system showing how the experiments are conducted. Fig. $2 \mathrm{~b}$ is the designed core holder for providing confining pressure and environmental temperature.

The coil diameters were $25 \mathrm{~mm}, 60 \mathrm{~mm}$ and $70 \mathrm{~mm}$ for the porosity and pore structure tests, gas adsorption and fluid transport experiments, respectively. The gas employed for the gas adsorption experiments was pure methane under gas pressures of $0.66 \mathrm{MPa}, 1.48 \mathrm{MPa}, 2.45 \mathrm{MPa}$, 4.45 MPa, 5.79 MPa, 7.76 MPa at room temperature $\left(25^{\circ} \mathrm{C}\right)$. The fluid transport experiments were conducted on the evacuated shale samples by water $\left(\mathrm{H}_{2} \mathrm{O}\right)$ injection with an injection pressure of $5 \mathrm{MPa}$ and a confining pressure of $7 \mathrm{MPa}$ at $25^{\circ} \mathrm{C}$. The magnetic resonance signals of water filled cores were recorded every hour, and finally ended at 7.3 h.

The pore structure of shale samples was observed and analyzed using a super-resolved field-emission SEM (FE-SEM, Hitachi SU8220), which revealed the pore structure such as pore size, shape, and its distribution. In addition, when combined with statistical methods, the porosity, the pore size, and its distribution, shape and curvature can also be obtained. At the same time the elemental components of shale samples were analyzed by the backscattered electron signals. The samples for the SEM observations were sliced into small blocks $\left(15 \times 10 \times 5 \mathrm{~mm}^{3}\right)$. Considering that the sample surfaces were uncoated with conductive coating and the abundant organic matters in the samples, the accelerating voltage was set relatively low with a close working distance. Since it is often hard to distinguish the nanopore from the anomalous morphology induced by mechanical polishing, we adopted ion beam milling technique (Hitachi IM4000) after polishing. The sample surface was bombarded by the accelerated argon ions and finally achieved a real profile beneath the surface with a "mirror surface" effect.

The characteristics of non-destructive analysis and three-dimensional

Table 1

The parameters of CPMG sequences for the NMR experiments.

\begin{tabular}{llll}
\hline & $\begin{array}{l}\text { Porosity and } \\
\text { pore structure } \\
\text { tests }\end{array}$ & $\begin{array}{l}\text { Gas adsorption } \\
\text { experiments }\end{array}$ & $\begin{array}{l}\text { Fluid transport } \\
\text { experiments }\end{array}$ \\
\hline Wait time (ms) & 2000 & 3000 & 1000 \\
Echo spacing (ms) & 0.10 & 0.20 & 0.25 \\
Number of trains & 16 & 16 & 64 \\
Number of echoes & 3000 & 16000 & 15000 \\
\hline
\end{tabular}



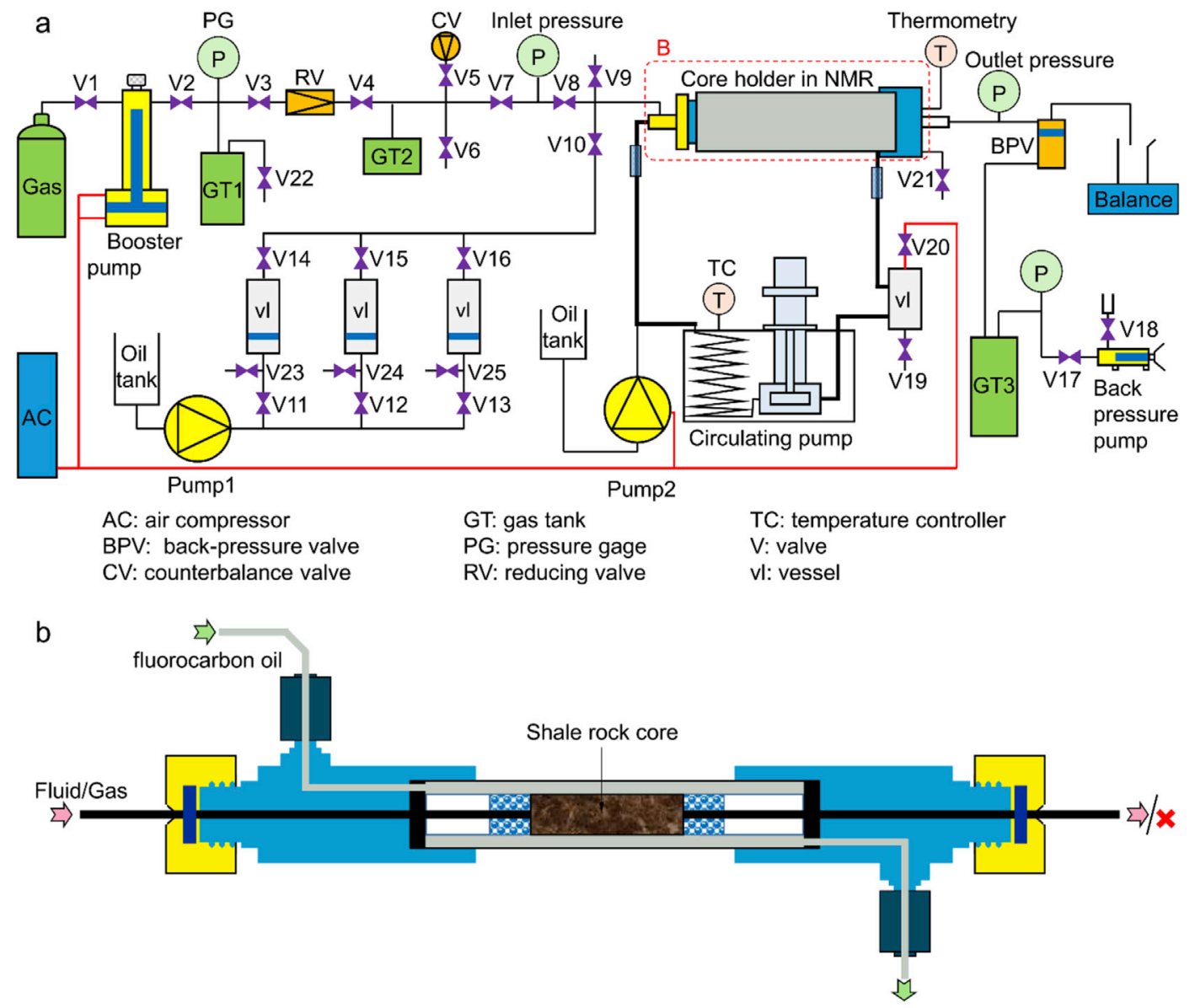

Fig. 2. (a) The NMR setups for adsorption experiments under different pressure. (b) The core holder in NMR for providing the confining pressure and environmental temperature.

reconstruction of CT make it very suitable for pore research of rocks. Therefore we employed the X-ray nano-CT to visualize the spatial distributions of pore structure, organic matters, and minerals of shale rocks. The X-ray nano-CT deals with the strong anisotropic characteristics of shale rocks effectively, and offers the continuous change of pore structure. The samples for X-ray nano-CT tests were drilled into $2 \mathrm{~mm}$ in diameter and $2 \mathrm{~mm}$ in length. The scanning of the shale samples was carried out with a modern compact laboratory CT system (General Electric phoenix nanotom M180). The system captured $600 \mathrm{X}$-ray images by incrementally rotating the shale sample through a full $360^{\circ}$. After that the intuitionistic three-dimensional model can be established based on these two-dimensional images which contains the information of position and density of absorbing object features within the samples.

\section{Theoretical models}

\subsection{Characterization of pore structure using nuclear magnetic resonance}

The NMR measurement gives a spectrum of attenuation times, i.e., the longitudinal relaxation time distributions $\left(T_{1}\right)$ and the transverse relaxation time distributions $\left(T_{2}\right)$. The relaxation time reflects the binding force and the degree of freedom of ${ }^{1} \mathrm{H}$ in the samples, which has a close relation with the internal structure of the samples. $T_{2}$ is more often used for measuring pore-throat size of porous media. Basically, there are three types of relaxation in porous media affected by the magnetic field gradient, which gives the $T_{2}$ as follows:

$\frac{1}{T_{2}}=\frac{1}{T_{2 B}}+\frac{1}{T_{2 D}}+\frac{1}{T_{2 S}}$ where $T_{2 B}, T_{2 D}, T_{2 S}$ are bulk, diffuse, and surface relaxations, respectively.

For LF-NMR measurements, the magnetic field is nearly homogeneous. Thus the relaxation time can be simplified as:

$\frac{1}{T_{2}} \approx \frac{1}{T_{2 S}}=\rho_{2} \frac{S}{V}$

where $\rho_{2}$ is the transverse surface relaxivity $\left(\mathrm{m} \cdot \mathrm{s}^{-1}\right)$ which relates to the abundance of paramagnetic ions on the pore surface, and $S / V$ refers to the surface to volume ratio of a pore $\left(\mathrm{m}^{-1}\right)$.

Magnetization decay of pores with different size and shape can be represented in the form of multi-exponential expression as (Yao et al., 2015):

$M(t)=\sum_{i=1}^{n} A_{i} \exp \left(-\frac{t}{T_{2 i}}\right)$

where $A_{i}$ is the numbers of protons in pores of size $i, T_{2 i}$ is the corresponding decay time constant which was deduced by Eq. (2). Thus a NMR measurement gives a $M(t)$ and then $T_{2}$ distribution.

\subsection{Adsorption model}

For adsorption gas that confined in pore structure of shale gas reservoirs, the fractional coverage can be described by Langmuir equation:

$\theta=\frac{p_{0} / Z}{p_{\mathrm{L}}+p_{0} / Z}$

where $p_{0}$ and $p_{\mathrm{L}}$ are pore pressure $(\mathrm{Pa})$ and Langmuir pressure $(\mathrm{Pa})$, 
respectively; $Z$ is the compressibility factor of gas.

\subsection{Scaling of the spontaneous imbibition of shale rocks}

The most often used dimensionless time for scaling spontaneous imbibition data in rock is given by:

$t_{\mathrm{D}}=\sqrt{\frac{k}{\phi}} \frac{\sigma}{\mu_{\mathrm{m}} L_{\mathrm{c}}^{2}} t$

where $k$ is the permeability of shale rocks (D), $\phi$ refers to the porosity, $\sigma$ is the surface tension of water (N/m), $\mu_{\mathrm{m}}$ is the water viscosity (Pa.s), $L_{\mathrm{c}}$ is the characteristic length (m) (Li and Horne, 2004), $t$ is the imbibition time (s).

Katz and Thompson (1986) proposed that the relationship between porosity and permeability of porous media is given as follows:

$k \approx 4.48 d^{2} \phi^{2}$

Combining eqs. (5) and (6), we obtain:

$t_{\mathrm{D}}=2.12 \frac{\sigma d \sqrt{\phi}}{\mu_{\mathrm{m}} L_{\mathrm{c}}^{2}} t$

here the variables can be classified into three groups: rock properties $(d$, $\phi)$, fluid properties $\left(\sigma, \mu_{\mathrm{m}}\right)$, and geometrical parameters $L_{\mathrm{c}}$.

Li and Horne (2004) developed a theoretical model which gives the relationship between the imbibition and the recovery:

$Q_{w}=\frac{\mathrm{d} N_{w t}}{\mathrm{~d} t}=a \frac{1}{U}-b$

$\left(1-\frac{b}{a} U\right) \mathrm{e}^{\frac{b}{a} U}=\mathrm{e}^{-t_{d}}$

with $a=\frac{A k\left(S_{w f}-S_{w i}\right)}{\mu_{\mathrm{m}} L} p_{c}, \quad b=\frac{A k}{\mu_{\mathrm{m}}} \Delta \rho g \sin \beta$,

$$
t_{d}=\frac{b^{2}}{a^{2}} \frac{k}{\phi} \frac{p_{c}}{\mu_{\mathrm{m}}} \frac{S_{w f}-S_{w i}}{L_{\mathrm{c}}^{2}} t
$$

where $Q_{w}$ is the imbibition rate $\left(\mathrm{m}^{3} / \mathrm{s}\right) ; N_{w t}$ is the volume of water imbibed $\left(\mathrm{m}^{3}\right) ; U$ is the recovery in terms of pore volume; $a$ and $b$ are two constants related to capillary and gravity forces, respectively; $A$ is the cross-sectional area of the core $\left(\mathrm{m}^{2}\right) ; S_{w f}$ is the water saturation behind the imbibition front; $S_{w i}$ is the initial water saturation; $p_{c}$ is the capillary pressure (Pa); $\Delta \rho$ is the density difference between water and gas in $(\mathrm{kg} /$ $\left.\mathrm{m}^{3}\right) ; g$ is the gravity acceleration $\left(\mathrm{m} / \mathrm{s}^{2}\right) ; \beta$ is the angle between the axis of the horizontal direction and the core sample; $t_{d}$ is the time with gravity and capillary force included.

\section{Results and discussions}

\subsection{Multiscale pore structure in shale gas reservoirs}

We characterized the multiscale pore structure and its size distribution of shale rocks using NMR, SEM, and nano-CT in combination, which provided the full-scale information of the complex pore structure of the shale gas reservoirs.

For NMR measurements of porosity, we first adopted standard gas concentrations of $15 \%, 10 \%, 6 \%, 3 \%, 1 \%$ to calibrate the relationship between the porosity and the signal amplitude, as shown in Fig. 3, which gives that:

$P=149.610 \phi+70.665 \quad$ with $R^{2}=0.999$,

where $P$ is the signal amplitude, $\phi$ is the porosity calibrated by the gas

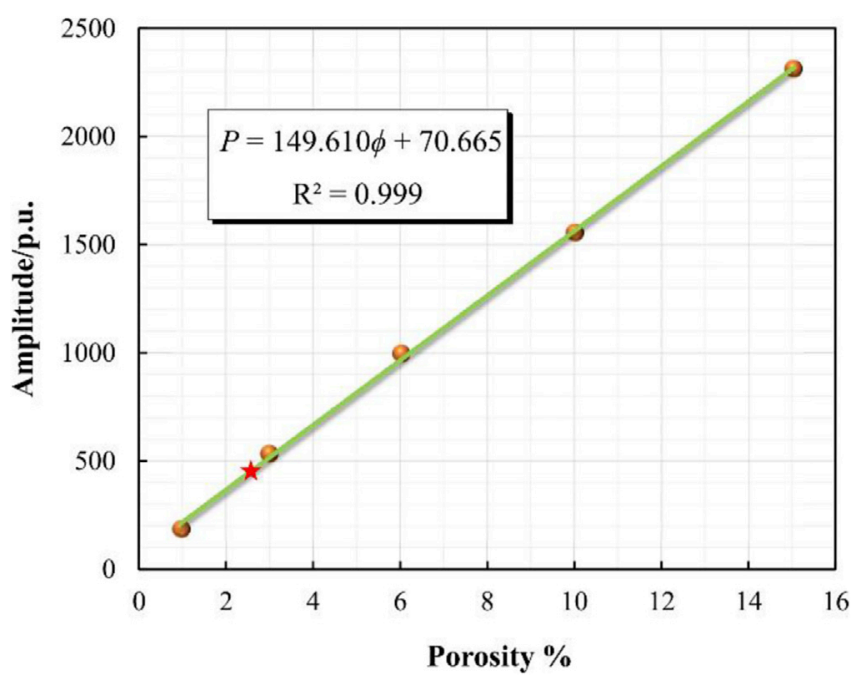

Fig. 3. Calibrated relationship between the porosity and the signal amplitude.

concentrations, $R^{2}$ is the coefficient of determination.

In this study, five shale samples were tested, which gave the porosity of $2.64 \%$ in average by the acquired signal amplitudes (marked with a red star in Fig. 3) using Eq. (4). The ultra-low porosity is far lower than the percolation threshold $(\sim 21.5 \%)$ for microcrack conductivity (Zhao et al., 2016).

Assuming that the pores are approximately cylindrical, therefore the distribution of the pore size can be derived by Eq. (2), as shown in Fig. 4. The pore size of the shale sample range from $1 \mathrm{~nm}$ to $10 \mu \mathrm{m}$ with two asymmetric peaks, at nanoscale $(<100 \mathrm{~nm})$ account for the majority of pore volume.

Considering eq. (6), the permeability of shale samples was calculated as $31 \mu \mathrm{D}$ assuming that $d \sim 100 \mathrm{~nm}$, much lower than that of conventional gas reservoirs.

Fig. 5 shows the SEM images of the iron beam milled shale samples. There are plenty of minerals (i.e., iron pyrites, bright white in Fig. 5a) accumulate in the matrix (i.e., clay, the large grey area in the SEM images of Fig. 5) to form a round berry shape, which the grain size is about $300 \mathrm{~nm}$. As shown in Fig. 5b, organic matters (i.e., kerogen, the black bands in Figs. 5b and c) are buried in the matrix of shale rocks. Besides, scattered minerals and organic matters can be found around the matrix, as well as minerals and clay are buried in the organic matters. The slit pores at sub-microscale were observed, as shown in Fig. 5d. Slit pores were also located at the junctions between kerogens and matrix, as shown in Fig. 5e. Figs. 5e and $\mathrm{f}$ shows the different types of pore structure

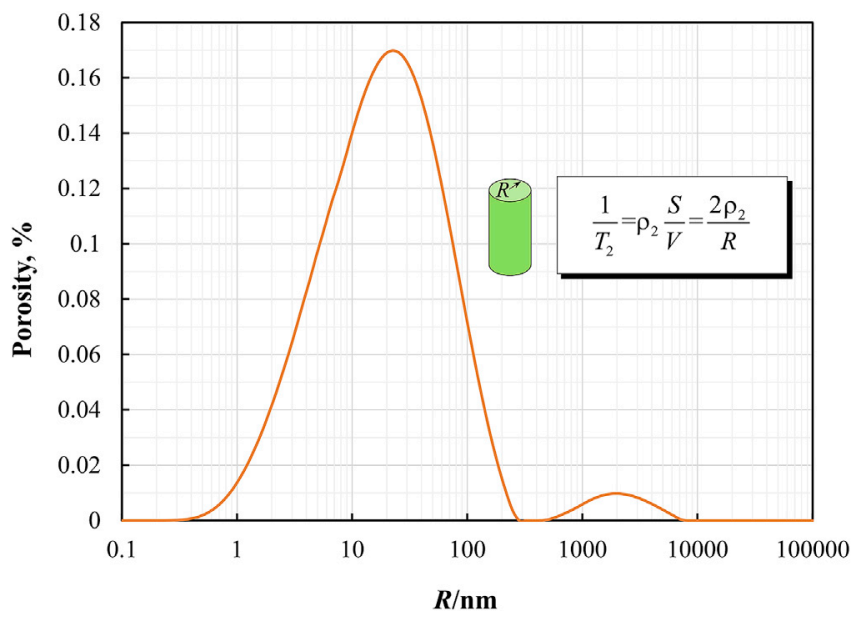

Fig. 4. Distribution of pore size for a shale sample. 


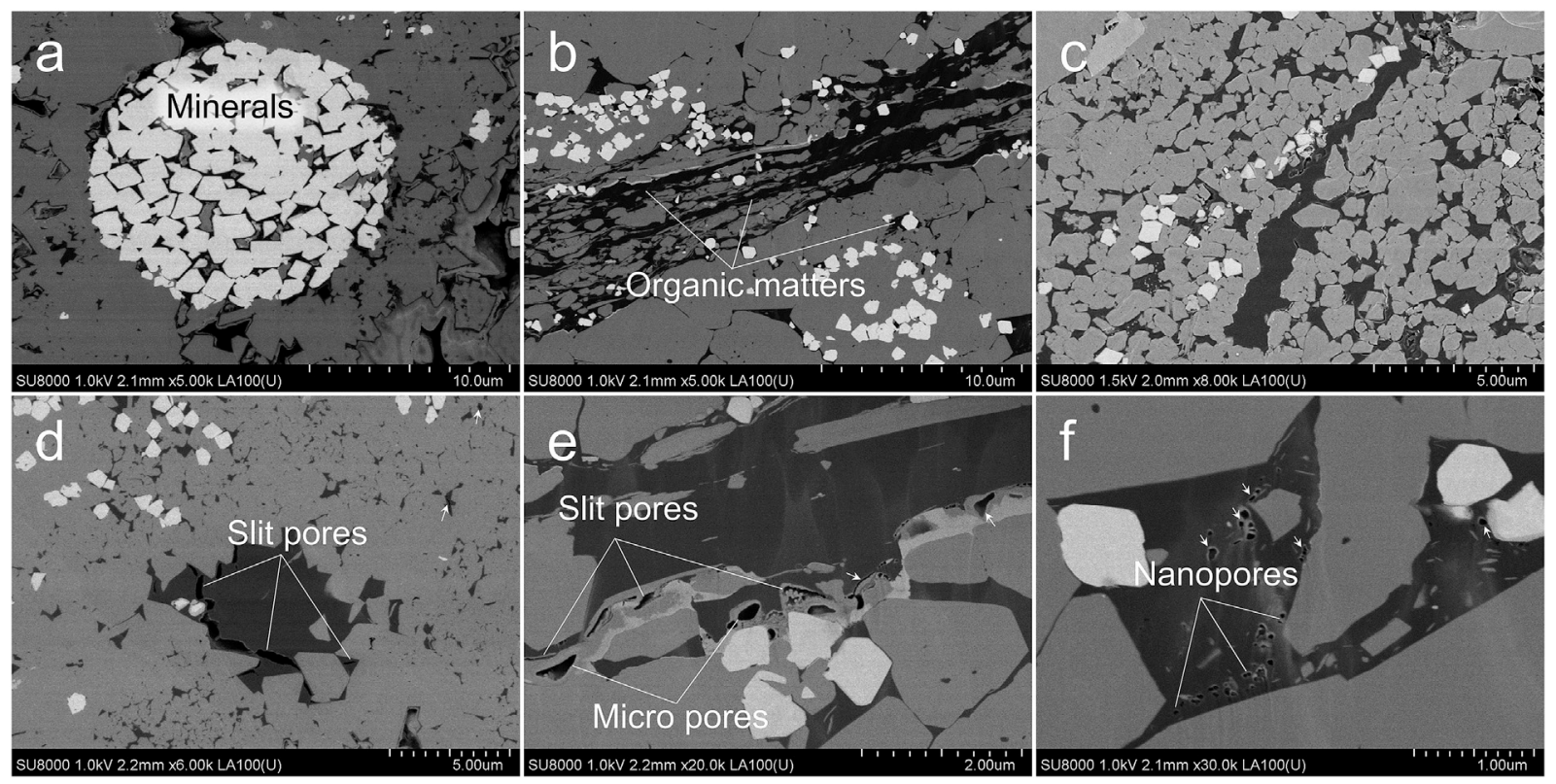

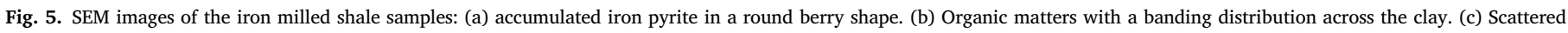
minerals and organic matters. (d) Slit pores in a kerogen. (e, f) Different types of pores at micro- and nanoscale.

in the shale gas reservoirs at microscale and nanoscale. It can be seen that inside the organic matters, there are circular and elliptical pores at a characteristic length of $20-100 \mathrm{~nm}$ distributed around the kerogen edge. However, due to the maturity of organic matters and the developing area of shale gas reservoirs under certain geological history, not every kerogen develops nanopore structure. Furthermore, there are also pores inside the matrix, i.e., the interparticle and intraparticle pores, which at a characteristic length of 10-1 $000 \mathrm{~nm}$ are distributed around the matrix and minerals.

More than $75 \%$ of the pore volume comes from the pore within the organic matters. These pores often take shape during the evolution of organic matters, and usually serve as gas cells and vents. Generally, there are relations between the total organic carbon (TOC) and the gas storage capacity. Fig. 6 shows a multiscale image of shale rock and their components. Fig. $6 \mathrm{~d}$ shows a schematic diagram of adsorption gas and free gas inner a nanopore of shale gas reservoirs. The large amount of nanopores in the organic matters enable the huge capacity of methane storage of shale gas reservoirs, which is present inside the nanopores as free gas, and adsorbed to the pore wall as adsorption gas.

The X-ray source was focused onto the internal region of the rock, and performed sequent scanning. Then the scanning images were used to establish intuitionistic three-dimensional model displaying the position and matters of interest within the shale sample, as shown in Fig. 7. We removed the artifacts and performed the beam hardening to the sequences of two-dimensional images and finally constructed the digital core of shale sample (see Fig. 7a). Since the CT image represents the energy attenuation during the X-ray passing through the sample, the grey scale of the image is positively correlated to the relative densities of the pore structure and the matters. Therefore, the three-dimensional distributions of minerals and the organic matters were mapped, as shown in Figs. $7 \mathrm{~b}$ and c, respectively. Their spatial distributions seem to be uniform in the rocks. Some parameters related to the shale gas reservoirs were evaluated based on the three-dimensional core model, as listed in Table 2.

The spatial distribution of pore structure was also clarified. Fig. 8 shows the pore space, the pores connectivity and the pore-throat of the shale rock, respectively. As can be seen in Fig. $8 \mathrm{c}$ that most of the pore throats were isolated in all directions with low continuity. It is why most of shale gas reservoirs are recovered by fracking technique.

\subsection{Occurrence state of shale gas under different gas pressures}

Gas injection to a porous media exhibits complex interaction of phase behavior (Dindoruk, 2015). To characterize the occurrence state of shale a
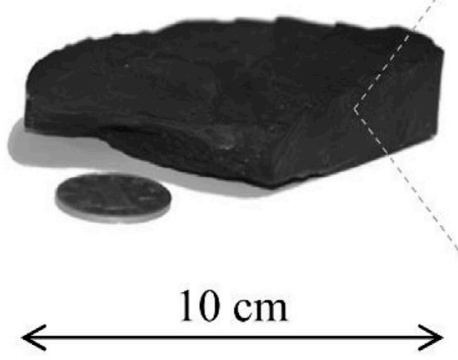

b
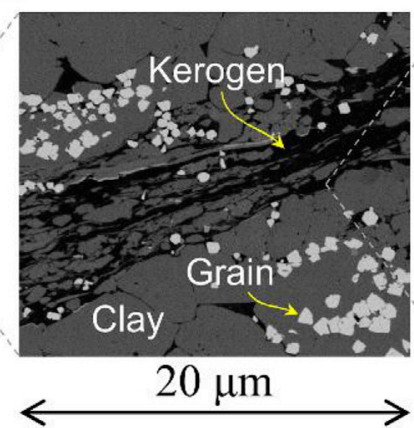

C

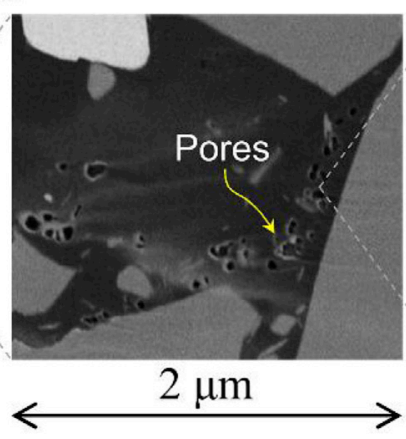

d

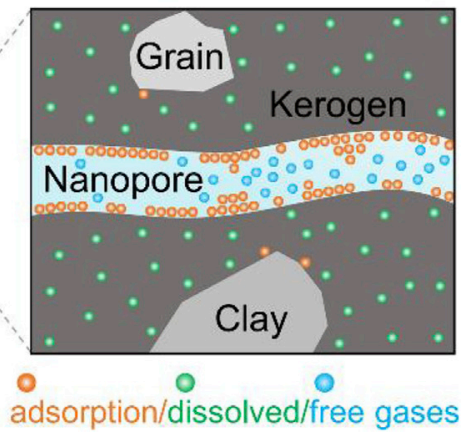

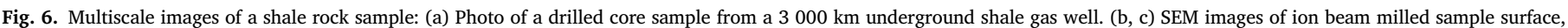

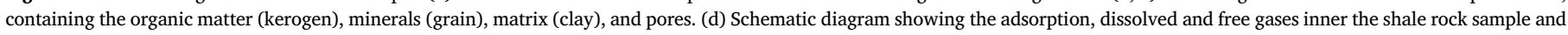
the nanopore. 
a

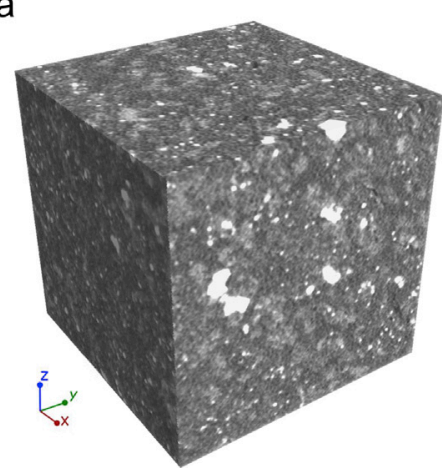

b

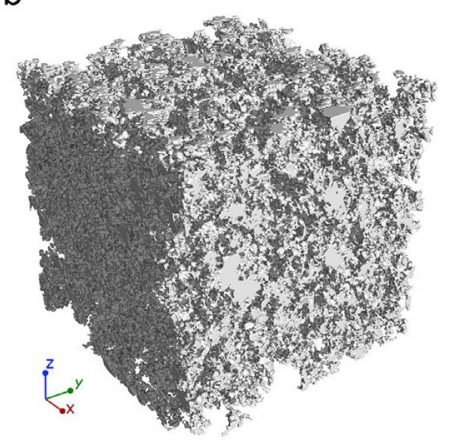

C

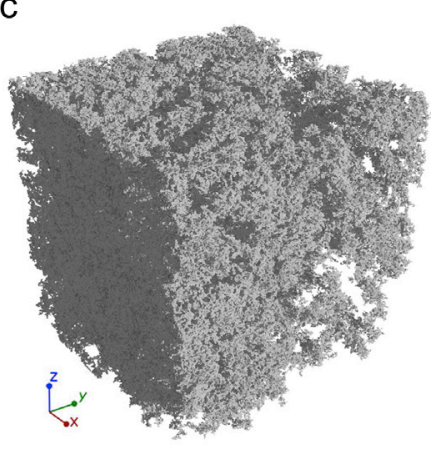

Fig. 7. (a) Digital core of the shale sample. (b, c) The three dimensional distributions of mineral and the organic matters, respectively.

Table 2

Parameters evaluated by the digital core model.

\begin{tabular}{|c|c|c|c|c|c|c|c|}
\hline \multicolumn{3}{|c|}{ Volume } & \multirow[b]{2}{*}{$\begin{array}{l}\text { Pore } \\
\left(\mu \mathrm{m}^{3}\right)\end{array}$} & \multicolumn{3}{|c|}{ Pore-throat } & \multirow[t]{2}{*}{ Total pores } \\
\hline $\begin{array}{l}\text { Digital core } \\
\left(\mathrm{mm}^{3}\right)\end{array}$ & $\begin{array}{l}\text { Organic matter } \\
\left(\mathrm{mm}^{3}\right)\end{array}$ & $\begin{array}{l}\text { Minerals } \\
\left(\mathrm{mm}^{3}\right)\end{array}$ & & $\begin{array}{l}\text { Av. length } \\
(\mu \mathrm{m})\end{array}$ & $\begin{array}{l}\text { Av. radius } \\
(\mu \mathrm{m})\end{array}$ & Count & \\
\hline 0.1380 & 0.0119 & 0.0265 & 109.87 & 13.61 & 0.7407 & 2897 & 9321 \\
\hline
\end{tabular}

a

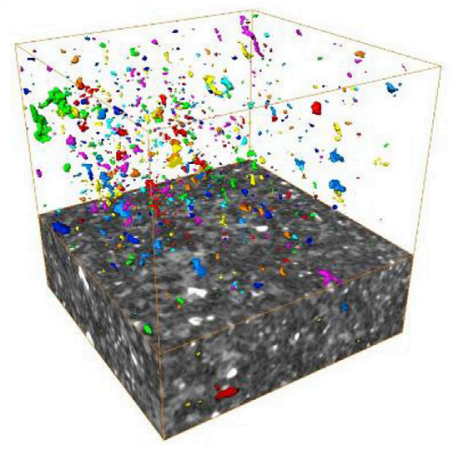

b

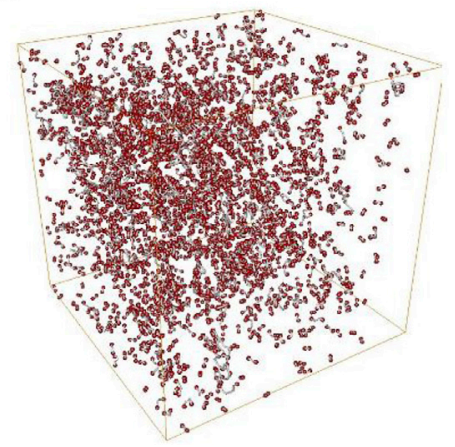

C

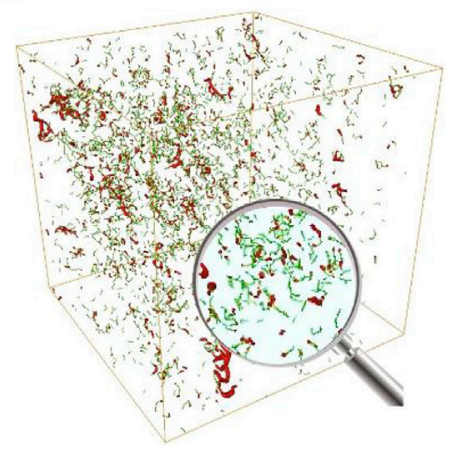

Fig. 8. (a) Pore space. (b) Pore connectivity. (c) Pore-throat.

gas in shale gas reservoirs under different gas pressures, pure methane was injected to the shale samples in designed NMR shale core holder.

The methane condition (adsorption or free) can be revealed by the $T_{2}$ spectrum of NMR, as shown in Fig. 9a. The results show that the contents of adsorption gas and free gas in the shale rocks were almost the same (53\%:47\%, see Fig. 9b) at relatively low gas pressures. Both their contents increased gradually with increasing gas pressure, of which the free gas increased faster after $\sim 1.5 \mathrm{MPa}$, and finally exceeded that of adsorption gas in the shale rocks (34\%:66\%, see Fig. 9b). The adsorption gas was approximately saturated at $\sim 4.45 \mathrm{MPa}$. It is because that as to Langmuir adsorption, only single-layer adsorption exists. As the adsorption amount increased, the adsorption sites on the pore wall approached saturation, while there was still large space in the pore center to fill with free gas.

\subsection{Spontaneous imbibition in gas shale}

The deionized water $\left(\mathrm{H}_{2} \mathrm{O}\right)$ was served as the probe to detect the $T_{2}$ signals which revealed the fluid transport behavior during the NMR measurements of imbibition in gas shale. Fig. 10 shows the $T_{2}$ spectrums over the spontaneous imbibition history.

In our experiment, the balance time of the whole imbibition was about $7 \mathrm{~h}$. For water at room temperature, $\sigma=71.97 \times 10^{-3} \mathrm{~N} / \mathrm{m}$, $\mu_{\mathrm{m}}=0.8937 \mathrm{mPa}$ s. And for our shale samples, $d \sim 100 \mathrm{~nm}$ and $L_{\mathrm{c}}=120 \mathrm{~mm}$. Therefore, we calculated the dimensionless time as 2.29 according to eq. (7).
During of the fluid transport process, the $T_{2}$ peaks shifted to the right. The right shift was faster at early stage of tests than that of later stage, and finally ended off. It is because that the capillary effect of the pore structure in shale rocks dominated the fluid flow at the early stage. When the head face of the rock core saturated with water $(\sim 5 \mathrm{~h})$, the spontaneous imbibition disappeared gradually. As the entire sample saturated, the $T_{2}$ signals became changeless. This may explain why the closing in after water flooding (Dong et al., 2011) is always the must in practical shale gas recovery.

The NMR measurement adopted in our study offers a possible experimental tool to study the correlation of the imbibition rate and the recovery, and is also potential to investigate the process of displacement in the gas shale.

\section{Conclusion}

We have experimentally studied the multiscale pore structure and its distribution in shale gas reservoirs. The results show that the porosity and connectivity of shale rocks are ultra-low. The pore size ranges in multiscale, of which at nanoscale account for the majority of the pore volume. Among them, nanopores within the organic matters make up the most of pore volume, which enable the huge capacity of methane storage of gas shale reservoirs. The slit pores in kerogens was observed. The spatial distributions of minerals and organic matters are homogeneous, and most of the pore throats are isolated with low continuity.

Gas adsorption and spontaneous imbibition experiments were also 

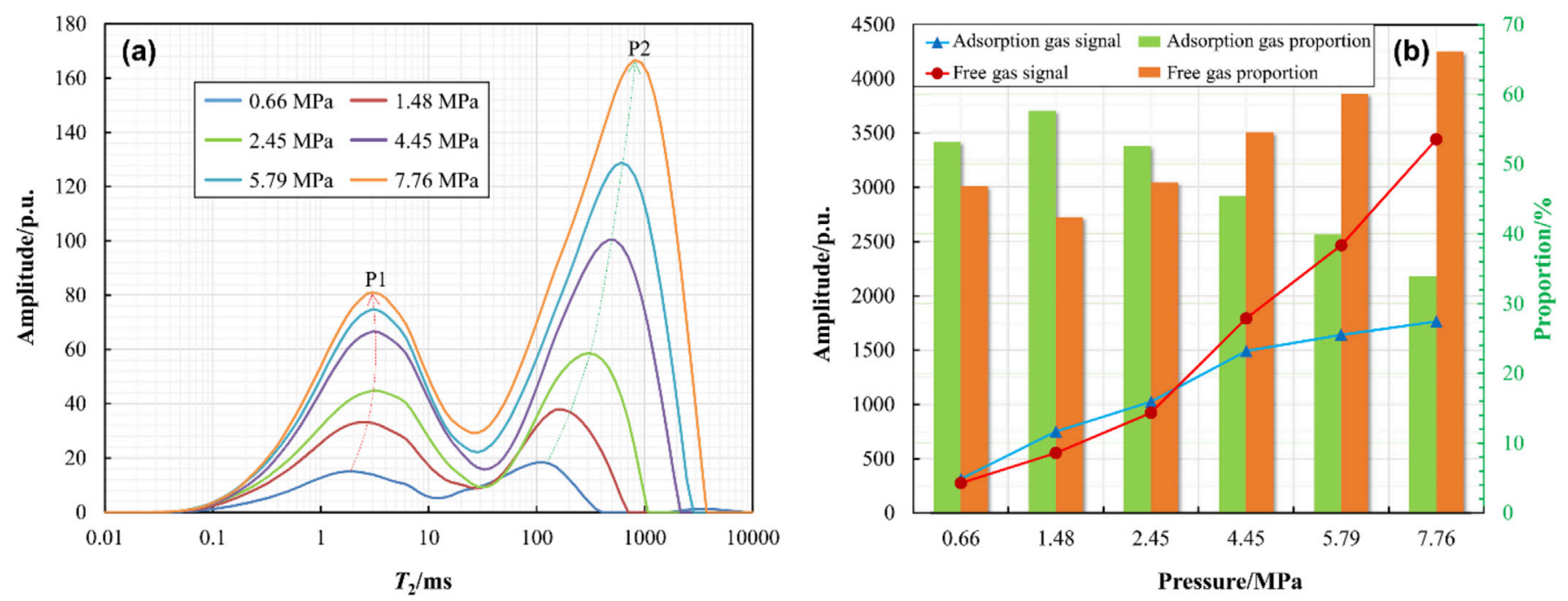

Fig. 9. (a) $T_{2}$ spectrum of methane under different gas pressures. (b) Proportions of adsorption gas and free gas under different pressures calculated by the gas signals.

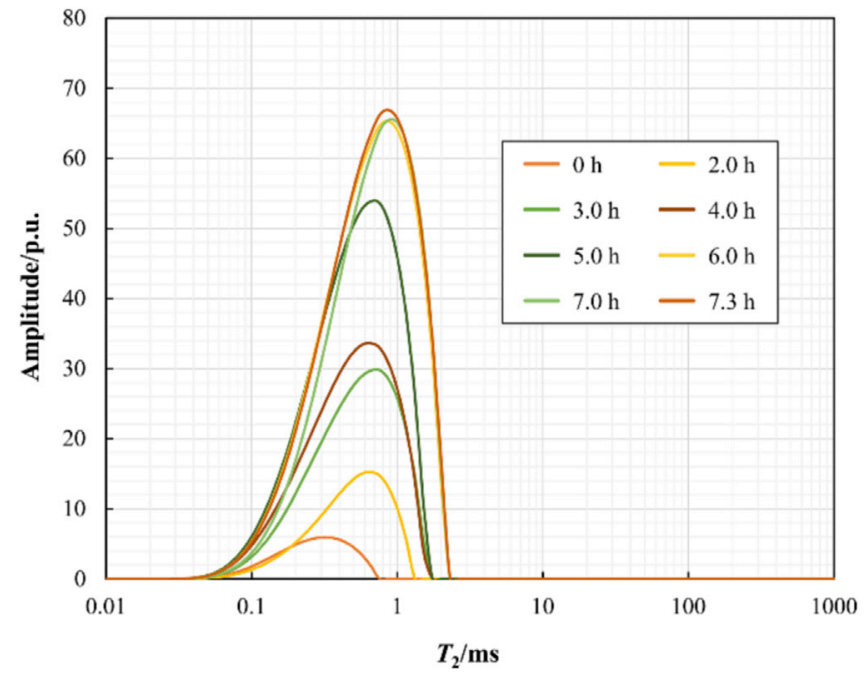

Fig. 10. $T_{2}$ spectrum over the fluid transport history through the shale rock.

carried out using NMR measurements to study the occurrence state of methane and the fluid transport behavior in the interconnected network of multiscale pore structure of shale gas reservoirs. The contents of adsorption gas and free gas are almost the same at relatively low gas pressure. Both their contents increase gradually with the increase of gas pressure, of which the free gas increases faster, and finally exceeds than that of adsorption gas. The spontaneous imbibition experiments indicate that the capillary effect dominates the early stage of the fluid transport, and then disappear gradually. Our results may provide unified methods for clear understanding of the pore structure and fluid transport behavior in shale gas reservoirs and assist the future efficient exploitation of shale gas.

\section{Acknowledgements}

This work was jointly supported by the National Natural Science Foundation of China (NSFC, Grant Nos. U1562105, 11702299, 11611130019 and 11372313), the Chinese Academy of Sciences (CAS) through CAS Interdisciplinary Innovation Team Project, the CAS Key Research Program of Frontier Sciences (Grant No. QYZDJ-SSW-JSC019), and the CAS Strategic Priority Research Program (Grant No. XDB22040401).

\section{References}

Ambrose, R.J., Hartman, R.C., Diaz Campos, M., Akkutlu, I.Y., Sondergeld, C., 2010. In New pore-scale considerations for shale gas in place calculations. In: SPE Unconventional Gas Conference. Society of Petroleum Engineers.

Bažant, Z.P., Salviato, M., Chau, V.T., Viswanathan, H., Zubelewicz, A., 2014. Why fracking works. J. Appl. Mech. 81 (10), 101010.

Chen, J., Wang, F., Liu, H., Wu, H., 2017. Molecular mechanism of adsorption/desorption hysteresis: dynamics of shale gas in nanopores. Sci. China Phys. Mech. 60 (1), 14611.

Darabi, H., Ettehad, A., Javadpour, F., Sepehrnoori, K., 2012. Gas flow in ultra-tight shale strata. J. Fluid Mech. 710, 641.

Das, J., 2012. Extracting natural gas through desorption in shale reservoirs. Way Ahead 8 (01), 11-13.

Dindoruk, B., 2015. Theory of Gas Injection: Interaction of Phase Behavior and Flow. AGU Fall Meeting Abstracts.

Dong, Y., Dindoruk, B., Ishizawa, C., Lewis, E.J., 2011. An experimental investigation of carbonated water flooding. In: SPE Annual Technical Conference and Exhibition. Society of Petroleum Engineers.

Javadpour, F., 2009. Nanopores and apparent permeability of gas flow in mudrocks (shales and siltstone). J. Can. Pet. Technol. 48 (08), 16-21.

Jiang, F., Chen, D., Chen, J., Li, Q., Liu, Y., Shao, X., Hu, T., Dai, J., 2016. Fractal analysis of shale pore structure of continental gas shale reservoir in the Ordos Basin, NW China. Energy Fuel 30 (6), 4676-4689.

Katz, A.J., Thompson, A.H., 1986. Quantitative prediction of permeability in porous rock. Phys. Rev. B 34 (11), 8179-8181.

Lee, T., Bocquet, L., Coasne, B., 2016. Activated desorption at heterogeneous interfaces and long-time kinetics of hydrocarbon recovery from nanoporous media. Nat. Commun. 7.

Li, K., Horne, R.N., 2004. An analytical scaling method for spontaneous imbibition in gas/ water/rock systems. SPE J. 9, 322-329.

Liu, J., Yao, Y., Elsworth, D., Pan, Z., Sun, X., Ao, W., 2016. Sedimentary characteristics of the lower cambrian niutitang shale in the southeast margin of sichuan basin, China. J. Nat. Gas. Sci. Eng. 36, 1140-1150.

Ma, Y., Zhong, N., Cheng, L., Pan, Z., Dai, N., Zhang, Y., Yang, L., 2016. Pore structure of the graptolite-derived OM in the longmaxi shale, southeastern upper yangtze region, China. Mar. Pet. Geol. 72, 1-11.

Maurel, O., Reess, T., Matallah, M., De Ferron, A., Chen, W., La Borderie, C., PijaudierCabot, G., Jacques, A., Rey-Bethbeder, F., 2010. Electrohydraulic shock wave generation as a means to increase intrinsic permeability of mortar. Cem. Concr. Res. 40 (12), 1631-1638.

Monteiro, P.J., Rycroft, C.H., Barenblatt, G.I., 2012. A mathematical model of fluid and gas flow in nanoporous media. P. Natl. Acad. Sci. U. S. A. 109 (50), 20309-20313.

Mosher, K., He, J., Liu, Y., Rupp, E., Wilcox, J., 2013. Molecular simulation of methane adsorption in micro-and mesoporous carbons with applications to coal and gas shale systems. Int. J. Coal Geol. 109, 36-44.

Ross, D.J., Bustin, R.M., 2007. Shale gas potential of the lower jurassic gordondale member, northeastern British Columbia, Canada. B. Can. Pet. Geol. 55 (1), 51-75.

Roychaudhuri, B., Tsotsis, T.T., Jessen, K., 2013. An experimental investigation of spontaneous imbibition in gas shales. J. Pet. Sci. Eng. 111, 87-97.

Sander, R., Pan, Z., Connell, L.D., 2017. Laboratory measurement of low permeability unconventional gas reservoir rocks: a review of experimental methods. J. Nat. Gas. Sci. Eng. 37, 248-279.

Sheng, M., Li, G., Huang, Z., Tian, S., Shah, S., Geng, L., 2015. Pore-scale modeling and analysis of surface diffusion effects on shale-gas flow in Kerogen pores. J. Nat. Gas. Sci. Eng. 27, 979-985.

Swami, V., Clarkson, C.R., Settari, A., 2012. In Non-Darcy flow in shale nanopores: do we have a final answer?. In: SPE Canadian Unconventional Resources Conference. Society of Petroleum Engineers. 
Tomain, J.P., 2012. Shale gas and clean energy policy. Case W. Res. L. Rev. 63, 1187. Wang, H., Marongiu-Porcu, M., 2015. Impact of shale-gas apparent permeability on production: combined effects of non-darcy flow/gas-slippage, desorption, and geomechanics. SPE Reserv. Eval. Eng. 18 (04), 495-507.

Wu, H., Chen, J., Liu, H., 2015a. Molecular dynamics simulations about adsorption and displacement of methane in carbon nanochannels. J. Phys. Chem. C 119 (24), 13652-13657.

Wu, K., Li, X., Wang, C., Yu, W., Chen, Z., 2015b. Model for surface diffusion of adsorbed gas in nanopores of gas shale reservoirs. Ind. Eng. Chem. Res. 54 (12), 3225-3236.

Yao, Y., Liu, D., Liu, J., Xie, S., 2015. Assessing the water migration and permeability of large intact bituminous and anthracite coals using NMR relaxation spectrometry. Transp. Porous. Med. 107 (2), 527-542.
Yuan, Q., Zhu, X., Lin, K., Zhao, Y.-P., 2015. Molecular dynamics simulations of the enhanced recovery of confined methane with carbon dioxide. Phys. Chem. Chem. Phys. 17 (47), 31887-31893.

Zeng, W.-T., Zhang, J.-C., Ding, W.-L., Wang, X.-Z., Zhu, D., Liu, Z., 2014. The gas content of continental Yanchang shale and its main controlling factors: a case study of Liuping-171 well in Ordos Basin. Nat. Gas. Geosci. 2, 291-301.

Zhao, Y.-P., Chen, J., Yuan, Q., Cheng, C., 2016. Microcrack connectivity in rocks: a realspace renormalization group approach for 3D anisotropic bond percolation. J. Stat. Mech.-Theory E. 2016 (1), 013205.

Zhu, X., Zhao, Y.-P., 2014. Atomic mechanisms and equation of state of methane adsorption in carbon nanopores. J. Phys. Chem. C 118 (31), 17737-17744. 